\title{
Papers
}

\section{Deprivation and late presentation of glaucoma: case-control study}

\author{
Scott Fraser, Catey Bunce, Richard Wormald, Eric Brunner
}

\begin{abstract}
Objective To identify socioeconomic risk factors for first presentation advanced glaucomatous visual field loss.

Design Hospital based case-control study with prospective identification of patients.

Setting Three hospital eye departments. Participants Consecutive patients newly diagnosed with glaucoma $(n=220)$. Cases (late presenters) were those presenting with advanced glaucoma $(n=110)$, controls were those with early glaucoma $(n=110)$.

Results Median underprivileged area scores were higher among late presenters (29.5; interquartile range 9.0-42.2) than in the control group (21.3; 6.1-37.4) $(\mathrm{P}=0.035)$. Late presenters were more likely to be of lower occupational class (odds ratio adjusted for age and referral centre 20.1 (95\% confidence interval 2.6 to 155) for group III compared with group I-II and 86.0 (11.0 to 673 for group IV-V compared with group I-II), to have no access to a car $(2.2 ; 1.2$ to 4.0$)$, to have left full time education at age 14 or less $(7.5 ; 2.3$ to 24.7$)$, and to be tenants rather than owner occupiers (local authority tenants 3.2; 1.7 to 5.8 , private tenants $2.1 ; 0.7$ to 5.8). Effects of deprivation were partly accounted for by family history of glaucoma, time since last visit to an optometrist, and lack of an initial diagnosis of glaucoma by an optometrist.

Conclusions Area and individual level deprivation were both associated with late presentation of glaucoma. Existing evidence shows that late presentation is an important risk factor for subsequent blindness. Deprived groups thus seem to be at greater risk of going blind from glaucoma. Material deprivation may be associated with more aggressive disease as well as later presentation.
\end{abstract}

\section{Introduction}

Glaucoma is a disease with major importance in public health and accounts for $13 \%$ of all new registrations of blindness annually. ${ }^{1}$ It affects about $2 \%$ of Europeans aged 40 and over and some four times this proportion in African-Americans and African-Caribbeans. ${ }^{2}$ The European and US populations are ageing, and as prevalence of glaucoma is strongly linked with age ${ }^{34}$ the number of people blinded by the disease is set to increase.
End stage glaucoma causes a particularly profound and irreversible visual loss, but population studies show that only half of glaucoma sufferers are diagnosed and treated at any one time. ${ }^{5}$ Late presentation, when visual field loss threatens central vision, is an important risk factor for blindness related to glaucoma. ${ }^{6}$ Research into determinants of presentation with advanced glaucoma is scarce. We therefore designed this case-control study to determine both social and demographic risk factors as well as ocular and biological factors (presented elsewhere ${ }^{7}$ ). We report on the role of area deprivation and several measures of individual socioeconomic status in the stage of presentation with glaucoma in the hospital eye service. A link between deprivation and advanced glaucomatous visual field loss at first presentation would provide evidence for systematic inequity of access to effective hospital care. ${ }^{8}$

\section{Methods}

We carried out a prospective hospital based casecontrol study with recruitment at three independent eye departments in England (Moorfields Eye Hospital, London; Sunderland Eye Infirmary, Sunderland; Harold Wood Hospital, Essex) between September 1996 and May 1997. Participants were eligible for study if they were diagnosed with glaucoma according to the case-control criteria described in the box when they were first examined by the ophthalmologist. Those with a previous definite or possible diagnosis of glaucoma or ocular hypertension were not eligible. The optic disc criteria were shown, by a pilot study, to be good indicators of severity of disease. ${ }^{9}$ Intraocular pressure was obtained from the standard Goldmann tonometer reading at initial examination. We calculated that we needed 110 cases and 110 controls to provide $79 \%$ power to detect a threefold increase in the odds of late presentation in a factor present among $10 \%$ of the control group at the $5 \%$ level of significance (two tailed test).

Patients were excluded if they had problems performing the visual field test. This was defined as having more than one third fixation losses or one third false positive or one third false negative responses for glaucoma on visual field analysis.

We conducted the study prospectively to reduce selection and recall bias. Recruitment after the first of two visual field tests gave a consecutive series of cases
Glaxo Department
of Ophthalmic
Epidemiology,
Institute of
Ophthalmology,
University College
London, London
EC1V 2PD
Scott Fraser
clinical research fellow
Catey Bunce
medical statistician
Richard Wormald
director
International
Centre for Health
and Society,
Department of
Epidemiology and
Public Health,
University College
London, London
WC1E 6BT
Eric Brunner
senior lecturer
Correspondence to:
R Wormald
r.wormald@
ucl.ac.uk
BMJ 2001;322:639-43 


\section{Criteria for classification of glaucoma}

Cases (late presenters)

- Visual field loss consistent with a pattern of glaucomatous loss-for example, arcuate scotomas, residual temporal island-compatible with the patient's disc changes and in which there was no suggestion of other optic nerve pathology (for example, defects crossed the horizontal midline). For the late presenters, this field loss had to be within $5^{\circ}$ of fixation and beyond $30^{\circ}$ in one or both eyes

- Glaucoma of any chronic type-that is, primary open angle, pseudoexfoliative, normal tension, chronic angle closure, aphakic, or pigment dispersion

- Two consecutive fields (threshold or suprathreshold) confirming the loss, except when field loss was so advanced that field testing was not possible

- Cup:disc ratio assessed as $>0.8$ in the eye(s) with the field loss

Control group

- Visual field loss consistent with a pattern of glaucomatous loss, compatible with the patients disc changes and in which there was no suggestion of other optic nerve pathology. No absolute scotomas within $20^{\circ}$ of fixation in either eye

- Glaucoma of any chronic type as above

- Two consecutive fields (threshold or suprathreshold) confirming the loss

- Cup:disc ratio assessed as $>0.5$ or difference of $>0.2$ between the discs

and controls. All fields were examined by one author (SF) to ensure consistency of case definition. After patients gave their informed consent they were telephoned by a trained interviewer masked to the case-control status. The interviewer validated demographic data and asked a series of standard questions regarding socioeconomic status (occupational class, car access, and housing tenure), education (age at leaving full time education), ethnic origin (white European, African/African-Caribbean, and Asian), use of general medical services, and use of sight testing (optometric) services. There were no losses to telephone follow up. The study was approved by the ethics committee of Moorfields Eye Hospital.

\section{Referral}

The referral of most glaucoma patients to the hospital eye service in the United Kingdom is initiated by optometrists, usually after abnormal findings on sight tests. At the time of our study children under 16 years, people with diabetes, people on income support, and those with a first degree family history of glaucoma and over 40 years of age were exempt from sight test charges; optometrists claimed a fixed fee from the local health authority for these tests. Since this study, exemption has been extended to all people over 60 years of age.

Optometrists refer the patients to their general practitioners, who then refer them to the hospital eye service. Review of referral letters with telephone confirmation identified two principal referral sources: from an optometrist with or without a diagnosis of possible or probable glaucoma or from the general practitioner directly without an optometrist's referral and therefore without a diagnosis of glaucoma.

\section{Deprivation measures}

We used Jarman's underprivileged area score to classify deprivation. ${ }^{10}$ The score is based on weightings derived from general practitioners of the effects of eight census variables on workload in primary care. The variables (general practitioner ratings in brackets) are ward percentages of households with: elderly living alone (6.62), one parent families (3.01), children under 5 years (4.64), social class V (3.74), unemployment (3.34), overcrowded households (2.88), residents who had moved house within the year (2.68), and residents born in the Commonwealth (2.50). The underprivileged area score is calculated by linking individual postcodes with census data.

We used three factors to measure individual deprivation $^{11}$ : occupational class, housing tenure, and access to a car. The standard occupational classification assigns job titles to one of six categories. ${ }^{12}$ Occupational categories are: I-professional, II-managerial and technical, IIIN-skilled non-manual, IIIM-skilled manual, IV-partly skilled manual, and V-unskilled manual. Retired and unemployed participants and those on long term sick leave were assigned by their previous main occupation. Married women outside the labour market were classified by their husbands' occupation. Participants were combined into three groups: I-II, III, and IV-V.

Housing tenure was classified into three groups: owner occupier, private tenant, and local authority tenant. We considered that access to a car was unlikely to be confounded by fitness to drive as all participants were newly diagnosed at entry.

\section{Statistical analyses}

The effect of each socioeconomic factor on the likelihood of presenting with advanced glaucomatous field damage was estimated with unconditional logistic regression. ${ }^{11}$ We previously showed that late presentation was associated with referral type (not referred by an optometrist with a diagnosis of possible or probable glaucoma), family history (protective), and time since last visit to an optometrist. ${ }^{7}$ These factors were treated as covariates in this analysis. All analyses were conducted with STATA. ${ }^{13}$

\section{Results}

Table 1 summarises characteristics related to demography and glaucoma in the study sample (previously reported $^{7}$ )and the socioeconomic characteristics by case-control status. The Jarman score is presented as median (interquartile range); the higher the score, the greater the area deprivation. The largest single occupational group was III (skilled and non-skilled manual). Just over half had access to a car. Most participants had left full time education at the age of 14. Half were owner occupiers, and $41 \%$ were in council housing.

Table 2 shows the odds (adjusted for age and centre) of late presentation for each deprivation measure before and after adjustments. Lower socioeconomic status and education level was linked with late presentation, though for underprivileged area score this relation was weak. Adjustment for centre in the age adjusted models had a negligible effect on the odds ratio (data not shown). Precision of the risk estimates 
Table 1 Demographic and socioeconomic characteristics of study population. Medians are given with interquartile range

\begin{tabular}{|c|c|c|}
\hline Study factor & Controls $(n=110)$ & Cases $(n=110)$ \\
\hline \multicolumn{3}{|l|}{ Age (years): } \\
\hline$\leqslant 40$ & 8 & 9 \\
\hline $41-50$ & 16 & 6 \\
\hline $51-60$ & 26 & 7 \\
\hline $61-70$ & 27 & 27 \\
\hline $71-80$ & 29 & 47 \\
\hline $81-90$ & 4 & 14 \\
\hline Median & $63(52-71)$ & $72(63-88)$ \\
\hline \multicolumn{3}{|l|}{ Sex: } \\
\hline Male & 54 & 60 \\
\hline Female & 56 & 50 \\
\hline \multicolumn{3}{|l|}{ Ethnicity: } \\
\hline White & 98 & 73 \\
\hline African-Caribbean & 6 & 29 \\
\hline Asian & 6 & 8 \\
\hline \multicolumn{3}{|c|}{ Median intraocular pressure $(\mathrm{mm} \mathrm{Hg})$ : } \\
\hline Right eye & $22.5(20-26)$ & $27(22-35)$ \\
\hline Left eye & $23(20-26)$ & $28(23-34)$ \\
\hline Maximum & $25(22-27)$ & $30(25-38)$ \\
\hline \multicolumn{3}{|c|}{ Family history of glaucoma: } \\
\hline No & 58 & 89 \\
\hline Yes & 48 & 17 \\
\hline \multicolumn{3}{|l|}{ Referral source: } \\
\hline $\begin{array}{l}\text { Optometrists with } \\
\text { correct diagnosis }\end{array}$ & 100 & 63 \\
\hline Other & 10 & 47 \\
\hline \multicolumn{3}{|c|}{ Last visit to optometrist (years ago): } \\
\hline 1 & 27 & 12 \\
\hline 2 & 45 & 23 \\
\hline 3 & 16 & 10 \\
\hline 5 & 12 & 15 \\
\hline 6 & 0 & 1 \\
\hline 10 & 5 & 23 \\
\hline$>10$ or never & 5 & 26 \\
\hline Median UPA score & $21.3(6.1-37.4)$ & $29.5(9.0-42.2)$ \\
\hline \multicolumn{3}{|l|}{ Access to car: } \\
\hline Yes & 73 & 48 \\
\hline No & 37 & 62 \\
\hline \multicolumn{3}{|l|}{ Occupational group: } \\
\hline 1 & 5 & 0 \\
\hline II & 27 & 1 \\
\hline III & 56 & 42 \\
\hline IV & 12 & 29 \\
\hline V & 10 & 38 \\
\hline \multicolumn{3}{|c|}{ Age at leaving full time education: } \\
\hline$<14$ & 4 & 18 \\
\hline $14-15$ & 63 & 74 \\
\hline $16-17$ & 23 & 14 \\
\hline$\geqslant 18$ & 20 & 4 \\
\hline \multicolumn{3}{|l|}{ Housing tenure: } \\
\hline Owner & 70 & 41 \\
\hline Private rental & 8 & 10 \\
\hline Local authority rental & 32 & 59 \\
\hline
\end{tabular}

UPA=underprivileged area score.

for occupational status is poor because there was only one late presenter in group I-II. Ethnicity, added in model 2, accounted for about a quarter of the log odds of late presentation associated with education level and council tenancy. Model 3 also adjusts for cognitive and behavioural factors ${ }^{7}$ to try to show the possible effect of aggressive disease. Compared with the results of model 1 , there was a substantial residual effect for occupational group while the effects of educational level and housing tenure were reduced.

\section{Discussion}

We found consistent evidence for an association between lower socioeconomic status and late presentation with glaucoma. Patients who presented with more advanced field loss had higher underprivileged area scores, lower occupational status, and lower education level and were less likely to have access to a car and more likely to be tenants. As in cancer, presentation with advanced glaucoma is associated with a poor prognosis. ${ }^{6} 1415$

The inverse association between socioeconomic status and late presentation can be interpreted in different ways. Firstly, socially patterned differences in health seeking behaviour are likely to operate. This was so for the reported use of optometry services in the general household survey (1991-4). ${ }^{16}$ Regular sight testing was associated with higher social class and in our present study greatly reduced the risk of late presentation.

Alternatively, long term deprivation may lead to more rapidly progressive and aggressive disease. The links between raised cortisol concentration, ocular hypertension, and glaucoma ${ }^{17}$ provide some support for a psychosocial mechanism mediated by altered hypothalamic-pituitary-adrenal function. ${ }^{18}$ Thus the possible "length bias," which could be an important determinant of both case and control status, might be driven by pathological mechanisms linked to social status.

How might socioeconomic factors, including educational deprivation, influence risk of late presentation? Leaving school by the age of 14 was no longer a significant predictor (model 3, table 2) after adjustment for recall of family history of glaucoma and time since last visit to the optometrist. Both factors are likely be influenced by level of education, which influences awareness of the disease and the need for regular sight testing. While the effects of education and occupation are correlated and therefore difficult to separate ${ }^{19}$ it is interesting to note that the risk factor associated with social status remained highly significant in the same

Table 2 Adjusted estimates of effects of socioeconomic factors on risk of late presentation with glaucoma

\begin{tabular}{|c|c|c|c|}
\hline \multirow[b]{2}{*}{ Study factor } & \multicolumn{3}{|c|}{ Odds ratio $(95 \% \mathrm{Cl})$} \\
\hline & Model $1^{*}$ & Model 2† & Model $3 \ddagger$ \\
\hline UPA/unit increase & $1.02(1.01$ to 1.04$)$ & 1.01 (1.0 to 1.03$)$ & 1.01 (0.98 to 1.02$)$ \\
\hline \multicolumn{4}{|l|}{ Access to car: } \\
\hline Yes & 1 & 1 & 1 \\
\hline No & 2.22 (1.24 to 3.96$)$ & $1.58(0.83$ to 3.00$)$ & 1.24 (0.57 to 2.67$)$ \\
\hline \multicolumn{4}{|l|}{ Occupational group: } \\
\hline$I-I I$ & 1 & 1 & 1 \\
\hline III & 20.1 (2.60 to 155) & 35.0 (3.56 to 344$)$ & $32.6(3.10$ to 343$)$ \\
\hline IV-V & 86.0 (11.0 to 673$)$ & $103(10.5$ to 1027$)$ & $69.2(6.67$ to 718$)$ \\
\hline \multicolumn{4}{|c|}{ Age at leaving full time education: } \\
\hline$\geqslant 14$ & 1 & 1 & 1 \\
\hline$<14$ & 7.47 (2.26 to 24.7$)$ & $4.39(1.01$ to 19.0$)$ & $3.52(0.65$ to 19.0$)$ \\
\hline \multicolumn{4}{|l|}{ Housing tenure: } \\
\hline Owner & 1 & 1 & 1 \\
\hline Private rental & $2.06(0.73$ to 5.83$)$ & $2.16(0.69$ to 6.79$)$ & $1.85(0.48$ to 7.10$)$ \\
\hline Local authority rental & 3.16 (1.73 to 5.77$)$ & 2.44 (1.27 to 4.71$)$ & 1.65 (0.76 to 3.61$)$ \\
\hline
\end{tabular}

UPA=underprivileged are score.

${ }^{*}$ Adjusted for age and centre

$\dagger$ Adjusted for age, centre, and ethnicity.

$\ddagger$ Adjusted for age, centre, ethnicity, recall of family history of glaucoma, referral source, and time since last sight test. 
model. This may suggest additional mechanisms such as a diet insufficient in micronutrients ${ }^{20}$ and lifetime stress, ${ }^{18}$ which add to the aggression of glaucoma in poorer people.

In addition to occupational status previously published results from this study ${ }^{7}$ indicated that intraocular pressure at presentation, family history of glaucoma, method of referral to hospital, and the number of years since the last visit to an optometrist were found to be independently associated with late presentation. The data strongly suggested an association between intraocular pressure and advanced field loss at presentation, with a 1.2 (1.12 to 1.28$)$ increase in the odds of late presentation per unit increase in $\mathrm{mm}$ $\mathrm{Hg}$ after adjustment for the other mentioned factors.

Those with a family history of glaucoma were found to be about one third $(0.29 ; 0.12$ to 1.28$)$ as likely to present with advanced field loss than those with no family history. People referred from any source, other than an optometrist with the correct diagnosis (of glaucoma), were estimated to be four and a half times more likely to be late attenders (adjusted odds ratio $4.53 ; 1.52$ to 13.48$)$. The data also provided strong evidence that the longer since the last visit to an optometrist the greater the likelihood of first presenting with advanced glaucomatous visual field loss (adjusted odds ratio per year $1.25 ; 1.10$ to 1.42 ).

We also found a strong association between African-Caribbean ethnic origin and late presentation. $^{7}$ The Baltimore Eye Study found African Americans to be at significantly increased risk of visual impairment. ${ }^{21}$ In our study sample ethnic origin accounted for some, but not all of the association between socioeconomic status and late presentation (table 2).

Our study adds to the sparse evidence that lower socioeconomic status is linked with increased risk of chronic eye disease $\mathrm{e}^{22}$ and extends it to include glaucoma. It has been shown previously that late presentation with amblyopia in childhood is linked with deprivation $^{23}$ and that adult urban Americans of lower social status have higher rates of visual impairment. ${ }^{21}$ Lower socioeconomic class is also associated with poor uptake of mammography and cervical screening, ${ }^{24}$ and social deprivation has been linked to later presentation of cancers including breast, ${ }^{25}$ colorectal, ${ }^{26}$ and skin. ${ }^{27}$

\section{Implications for health care}

Early detection of glaucoma is clearly desirable, but the means to achieve this on a population basis remains problematic. Not only is there a lack of a single adequate screening tool but it is not clear how the test can be delivered to those most in need ${ }^{28}$ Optometrists are encouraged by their council to perform diagnostic testing for glaucoma on all their patients aged over 40 who present for routine sight testing. This places a strain on both optometrists and the hospital eye service as a result of false positive referrals. ${ }^{29} \mathrm{~A}$ further major problem, the lack of good evidence for the effectiveness of lowering intraocular pressure, is being tackled in a Swedish trial (early manifest glaucoma trial, www.nei.nih.gov/neitrials).

\section{Conclusions}

This hospital based case-control study is appropriate because it analyses factors for late presentation to

\section{What is already known on this topic}

Late presentation with glaucomatous field loss is an important risk factor for subsequent blindness

Relatively little is known about why certain patients present with advanced field loss while others present with early loss

\section{What this study adds}

Area and individual level deprivation are linked with presentation to the hospital eye service with advanced glaucoma

People with the least material and psychosocial resources seem to be at greatest risk of going blind from glaucoma

hospital. A weakness of our study is that it examines access only to the NHS. There was only one case from occupational group I-II, which might indicate that those from higher social groups with advanced disease may seek private health care. We cannot know whether selection bias led to an underestimate or overestimation of the effect of individual social deprivation. The fact that in the control group there were 33 participants from the higher socioeconomic groups suggests that this source of bias is unlikely to be serious.

To our knowledge, this study is the first to report that those with the least material and psychosocial resources to cope with blindness are at substantially higher risk of glaucomatous visual loss. Equity of access to effective health care is an enduring principle of the NHS. ${ }^{30}$ Our results suggest that glaucoma should be included among conditions targeted in policy aimed at reducing social inequalities in health.

We thank Peter Phelan (Sunderland Eye Infirmary), Rod Daniel (Moorfields Eye Hospital), and Charles Claoué (North East London Eye Partnership) for their enormous help in recruitment of the patients.

Contributors: All the authors contributed to the design of this study and wrote the paper jointly. RW and SF initiated the research. SF, RW, and EB designed the patient questionnaires. SF was responsible for coordinating the study and recruiting the patients. CB provided the data analysis. RW is the guarantor.

Funding: International Glaucoma Association and Moorfields Locally Organised Research Scheme. EB is supported by the British Heart Foundation.

Competing interests: None declared.

1 Evans J, Rooney C, Ashwood F, Dattani N, Wormald R. Blindness and partial sight in England and Wales: April 1990-March 1991. Health Trends 1996;28:5-12.

2 Sommer A, Tielsch JM, Katz J, Quigley HA, Gottsch JD, Javitt J, et al. Relationship between intraocular pressure and primary open angle glaucoma among white and black Americans. Arch Ophthalmol 1991;109:1090-5.

3 Tielsch JM, Sommer A, Katz J, Quigley HA, Royall RM, Javitt J. Racial variations in the prevalence of primary open angle glaucoma. JAMA 1991;266:369-74.

4 Klein BEK, Klein R, Sponsel WE, Franke T, Cantor LB, Martone J, et al. Prevalence of glaucoma. Ophthalmology 1992;99:1499-504.

5 Tielsch JM. The epidemiology of primary open angle glaucoma. Ophthalmol Clin North Am 1991;4:649-57.

6 Grant WM, Burke JF. Why do some people go blind from glaucoma? Ophthalmology 1982;89:991-8.

7 Fraser SG, Bunce CV, Wormald RPL. Risk factors for late attendance of chronic glaucoma. Invest Ophthalmol Vis Sci 1999;40:2251-7.

8 Smeeth L, Heath I. Tackling health inequalities in primary care. BMJ 1999;318:1020-1.

9 Fraser SG, Bunce CV, Wormald RPL. Retrospective analysis of risk factors for late presentation of chronic glaucoma. $\mathrm{Br} J$ Ophthalmol 1999;83:24-8

10 Jarman B. Identification of underprivileged areas. BMJ 1983;286:1705-9. 
11 Sloggett A, Joshi H. Higher mortality in deprived areas: community or personal disadvantage? BMJ 1994;309:1470-4.

12 Office of Population Censuses and Surveys. Standard occupational classification. London: HMSO, 1991.

13 Stata Corporation. Stata statistical software release 5.0. College Station, TX: StataCorp, 1997.

14 Wilson R, Walker A, Dueker DK, Pitts-Crick R. Risk factors for rate of progression of glaucomatous visual field loss. Arch Ophthalmol 1982;100:737.

15 Mikelburg FS, Schulzer M, Drance SM, Lau W. The rate of progression of scotomas in glaucoma. Am J Ophthalmol 1986;101:1-6.

16 General household survey: analysis of ophthalmic data 1990-91 to 1993-94. London: Government Statistical Service, July 1995.

17 Schwartz B, McCarty G, Rosner B. Increased plasma free cortisol in ocular hypertension and open angle glaucoma. Arch Ophthalmol 1987:105:1060-5.

18 Brunner EJ, Marmot MG. Social organisation, stress and health. In: Marmot MG, Wilkinson RG, eds. Social determinants of health. Oxford: Oxford University Press, 1999.

19 Davey Smith G, Phillips AN. Confounding in epidemiological studies: why "independent" effects may not be all they seem. BMJ 1992;305:757-9.

20 Stallone DD, Brunner EJ, Marmot MG, Bingham SA. Dietary assessment in Whitehall II: the influence of reporting bias on apparent socioeconomic variation in nutrient intakes. Eur J Clin Nutr 1997;51: $815-25$
21 Tielsch JM, Sommer A, Katz J, Quigley H, Ezrine S. Socioeconomic status and visual impairment among urban Americans. Arch Ophthalmo 1991;109:638-41.

22 Quigley H, West S, Rodriguez J, Munoz B, Klein R, Snyder R. Prevalence of glaucoma in a population-based study of Hispanics. ARVO abstract 2896; March 2000.

23 Smith LK, Thompson JR, Woodruff G, Hiscox F. Social deprivation and age at presentation in amblyopia. J Public Health Med 1994;16:348-51.

24 Calle EE, Flanders WD, Thun MJ, Martin LM. Demographic predictors of mammography and Pap smear screening in US women. Am J Public Health 1993:83:53-60.

25 Wells BL, Horm JW. Stage at diagnosis in breast cancer: race and socioeconomic factors. Am J Public Health 1992;82:1383-5.

26 Powe BD. Fatalism amongst elderly African-Americans. Effects on colorectal cancer screening. Cancer Nursing 1995;18:385-92.

27 Robinson JK, Altman JS, Rademaker AW. Socioeconomic status and attitudes of 51 patients with giant basal and squamous cell carcinoma and paired controls. Arch Dermatol 1995;131:428-31.

28 Wormald RPL, Rauf A. Glaucoma screening. J Med Screen 1995;2:109-14

29 Griffiths PG. A surfeit of screening? BMJ 1997;315:318.

30 Report of the independent inquiry into inequalities in health. London: Stationery Office, 1998 (Acheson report).

(Accepted 14 December 2000

\title{
Duration of breast feeding and arterial distensibility in early adult life: population based study
}

\author{
C P M Leeson, M Kattenhorn, J E Deanfield, A Lucas
}

\begin{abstract}
Objectives To test the hypothesis that duration of breast feeding is related to changes in vascular function relevant to the development of cardiovascular disease.

Design Population based observational study. Setting Cambridge.

Participants 331 adults (171 women, 160 men) aged between 20 and 28 years, born in Cambridge

Maternity Hospital.

Main outcome measures Distensibility of brachial artery, type and duration of infant feeding, current lipid profile, and other cardiovascular risk factors. Results The longer the period of breast feeding the less distensible the artery wall in early adult life, with no sex differences (regression coefficient $=-3.93$ $\mu \mathrm{m} / \mathrm{month}, 95 \%$ confidence interval -7.29 to -0.57 , $\mathrm{P}=0.02)$. However, in those breast fed for less than four months, arterial distensibility was not significantly reduced compared with an exclusively formula fed group. The vascular changes observed were not explained by alterations in plasma cholesterol concentration in adult life.

Conclusions Breast feeding in infancy is related to reduced arterial function 20 years later. These data should not alter current recommendations in favour of breast feeding, which has several benefits for infant health. Further work is needed, however, to explore the optimal duration of breast feeding in relation to cardiovascular outcomes.
\end{abstract}

\section{Introduction}

Nutrition in early postnatal life may have major, long term "programming" effects on the physiology, metabolism, and clinical outcome of animals and humans. ${ }^{1-3}$ Coronary artery disease is one outcome in humans linked to early growth and nutrition. Although breast feeding has been associated with a lower risk of cardiovascular disease, men born earlier this century who had still been breast fed aged 1 year had higher rates of ischaemic heart disease $60-70$ years later compared with the expected rate for men of that age. ${ }^{2}$ If this observation were causal, it would raise an important question about the optimal duration of breast feeding.

Although observational evidence linking early nutrition to later cardiovascular disease might be subject to confounding, experimental evidence also exists linking atherosclerosis and breast feeding in non-human primates. Studies in baboons that were breast fed or formula fed throughout infancy and then placed on a Western style diet, high in saturated fats, showed that those previously breast fed had an abnormal lipid profile and more arterial fatty streaks in adulthood. ${ }^{1}$ One hypothesis was that breast feeding programmed baboons to be conservative with cholesterol-perhaps appropriately for their natural diet-but when they consumed a Western diet this programming led to arterial disease. Were these findings supported in humans, it would have implications for infants weaned on to a Western diet.

We studied a UK population to test further the hypothesis that duration of breast feeding might influence later emergence of vascular disease. To minimise potential influences of other lifestyle factors throughout adulthood we studied a young cohort. This was feasible because early pathophysiological changes in the artery, relevant to the development of atherosclerosis, can now be measured early in life with non-invasive imaging techniques. ${ }^{45}$ Our group has already shown links between vascular dysfunction and growth and nutrition during childhood. ${ }^{67}$ In this study, we
Editorial by Booth

Medical Research Council Childhood Nutrition Research Centre, Institute of Child Health,

London

WC1N 1EH

C P M Leeson research fellow

A Lucas professor

Vascular Physiology Unit, Great Ormond Street Hospital for Children, London WC1N 3JH

M Kattenhorn vascular technician J E Deanfield professor

Correspondence to: C P M Leeson cpm_leeson@ hotmail.com

BMJ 2001;322:643-7 